\title{
Tide-induced changes in marine fish cage- shape cause changes in swimming behavior of cultured chub mackerel (Scomber japonicus)
}

\author{
Bo-Kyu Hwang ${ }^{1}$, Jihoon Lee $2^{2^{*}}$ and Hyeon-Ok Shin ${ }^{3}$
}

\begin{abstract}
We performed field measurements of the behavioral changes in cultured chub mackerel (Scomber japonicus) caused by tide-induced changes in the shapes of their small-sized tetragonal fish cages. The field measurements were conducted in two separate periods: neap tide, a period in which the shape of the fish cages was stable; and spring tide, a period in which the fish cages are significantly deformed, which was expected to have significant influences on fish behavior. In the spring tide, the cages were deformed greatly by the moving water, with different water velocities affecting the cages to different degrees; the volume loss was estimated at $4.9 \%$ and $7.3 \%$ for $v=0.114 \mathrm{~m} /$ $\mathrm{s}$ and $v=0.221 \mathrm{~m} / \mathrm{s}$, respectively. The fish exhibited significantly different behaviors between the neap tide and spring tide. During the neap tide, the fish remained in the lower part of the cage, but during the spring tide they made frequent upward and downward movements, and their horizontal distribution changed significantly due to the changes in the shape of the cage. The cage deformation during the spring tide greatly influenced the swimming behavior of fish.
\end{abstract}

Keywords: Acoustic positioning system, Aquaculture, Fish cage deformation, Fish behavior, Fish welfare

\section{Introduction}

One continuous sea surface fish culture technique, marine cage culture, is conducted for many commercially valuable fish. In a marine cage aquaculture system, the mechanical stability of the cage and the maintenance of a stable feeding environment are the most important factors, and thus, are the most basic conditions to be considered at the time of the manufacture and installation of the cage system. The marine cage facility should be installed in a hydraulically stable semi-enclosed coastal and inner bay area where the waves and currents are weak, in order to avoid damage and loss of facilities from strong currents or waves (Anras and Lagardère

\footnotetext{
* Correspondence: jihoon.lee@jnu.ac.kr

2 Department of Marine Porduction of Management, Chonnam National University, 50 Daehak-ro, Yeosu 59626, Korea

Full list of author information is available at the end of the article
}

2004). In addition, an appropriate amount of sinking force (weight) is applied to maintain the shape and volume of the cage, that is, to keep the structure and capacity of the cage as stable as possible.

Despite of these efforts, a marine cage system cannot avoid the influences of the tide and waves, and the entire cage system continuously faces the tidal force, and so, the shape of the cage net continuously changes.

Such cage deformation greatly reduces farming capacity (Lader et al. 2008; Gui et al. 2006); this decrease in cage space leads to decreased swimming space and increased stress in the cultured fish, which leads to growth depression (Conte 2004). In addition, high-density farming may lead to wounds in the fish due to collisions between cultured fish or between fish and the cage net; such injuries may considerably affect the health of the cultured fish, leading to disease or even death.

(c) The Author(s). 2020 Open Access This article is licensed under a Creative Commons Attribution 4.0 International License, which permits use, sharing, adaptation, distribution and reproduction in any medium or format, as long as you give

appropriate credit to the original author(s) and the source, provide a link to the Creative Commons licence, and indicate if changes were made. The images or other third party material in this article are included in the article's Creative Commons licence, unless indicated otherwise in a credit line to the material. If material is not included in the article's Creative Commons licence and your intended use is not permitted by statutory regulation or exceeds the permitted use, you will need to obtain permission directly from the copyright holder. To view a copy of this licence, visit http://creativecommons.org/licenses/by/4.0/ 
Furthermore, cage deformation affects the natural circulation of seawater into and out of the cage, which means that oxygen is not smoothly supplied to the cage; this, in turn, greatly affects the growth and pathogenesis of the fish.

Studies on marine cage systems have mainly been conducted to evaluate the stability of the cage by analyzing the changes in the shape of the cage net. Researchers have performed studies using scale-down models of fish cages to investigate their stability and shape changes caused by the tide and waves; recently, it has become possible to estimate these changes using computer simulations (Kim et al. 2001a; Kim et al. 2001b; Lee et al. 2015; Lee et al. 2008; Bi et al. 2015; Zhao et al. 2015; Lee et al. 2017). In addition, there are numerous methods to assess the behavior and change in volume of real cage nets using recent advances in underwater measurement technology; examples of this technology include highprecision pressure sensors (Lader et al. 2008) and underwater ultrasonic position measurement systems (Hwang and Shin 2003; Tae and Shin 2006; Miyamoto et al. 2006; Lee et al. 2017).

How fish respond to the behavior of the cage net is also an important area of research. The effects of cage deformation on the fish are not well known, although there have been some studies on the behavioral characteristics of salmon in cages (Juell and Westerberg 1993; Cubitt et al. 2005; Johansson et al. 2014). It is necessary to understand the effects that the changes in the shape of cages have on fish behavior, and to, subsequently, minimize these effects. The influence of coastal environmental pollution has increased in recent years as fish cages have been installed further out to sea. In particular, it is necessary to pay attention to the change in the swimming behavior of cultured fish according to the changes in the shape of the cage because the cage culture technique is used for tuna, a high value-added fish that swims at a relatively high speed.

Recently, mackerel has gained popularity for consumption as raw fish in Korea, and thus, has attracted attention as a high value-added species of increasingly good quality. In neighboring Japan, mackerel is also receiving attention as an important aquaculture species.

In this study, we observed the changes in the shape of marine cage nets due to the tide, using a 3D underwater position measurement system, and examined the changes in the swimming behavior of the mackerel to investigate and analyze how fish cage deformation affects the behavioral characteristics of cultured fish.

\section{Materials and methods}

\section{Experimental area and system setup}

Field experiments were conducted at a marine cage facility in the coastal area of Tongyoung in Gyeongsangnam- do, South Korea. The coastal area of Tongyoung has Korea's most developed marine cage culture system, and a number of culture facilities are installed there.

The shape of the cage system and the layout of the equipment used in the experiment are shown in Fig. 1. This facility contains a large cage system maintained for research and development of coastal marine resources; cages of various sizes are attached to one another and are connected with a plastic structure. The cage system is installed in a manner such that one side of the tetragonal cage is parallel to $330^{\circ}$ (left side in Fig. 1).

A radio-linked acoustic positioning system (VRAP, Vemco Ltd., Canada) and recording current meter (RCM-9, Aanderaa, Norway) were used to observe the swimming behavior of the cultured chub mackerel (Scomber japonicus) in the cage. The VRAP is an underwater position measurement system that uses an LBL (long baseline) method, which consists of three sea stations and one base station. Each sea station, in this study, was a buoy (RAP buoy) loaded with an omnidirectional hydrophone and installed on the sea surface; it received signals from transmitters. The base station controlled each sea station using a VHF modem; it received data from the sea stations and processed the data. To measure the current speed, direction, water temperature, cloudiness, and conductivity, a recording current meter was installed $5 \mathrm{~m}$ below the water surface outside of the cage; it recorded every $5 \mathrm{~min}$.

The shape of the cage and the positions of the ultrasonic transmitters (P1-P8) attached to the cage, which were the targets of the experiment, are shown in Fig. 2. The cage for the experiment was a small fish culture cage, the type most commonly used along the Korean coast. Its shape was a cube, $6 \mathrm{~m} \times 6 \mathrm{~m} \times 6 \mathrm{~m}(\mathrm{~L} \times \mathrm{W} \times$ $\mathrm{D})$, which is adequate for the chub mackerel housed in it. The cage was made of polyethylene net with a mesh size of $30 \mathrm{~mm}$ and a mesh diameter of $2 \mathrm{~mm}$, and each corner of the cage was tied with a rope having a sinker (W1-W4) weighing $15 \mathrm{~kg}$ and connected to the cage to minimize tide- and wave-induced cage deformation.

Typically, in the VRAP system, as the number of transmitters to be measured increases, greater interference occurs between signals according to different transmission periods of the transmitters. Therefore, the number of transmitters that can be used simultaneously is theoretically limited to ten (Jørgensen et al. 2007). A total of eight multi-purpose transmitters (V16-6H, Amirix Systems Inc., Canada) were used to record the movement of the cage. The transmitters were $95 \mathrm{~mm} \times 16 \mathrm{~mm}(\mathrm{~L} \times \mathrm{D})$ in size and weighed $34 \mathrm{~g}$. The transmitters were attached to the bottom of the cage (at a depth of $6 \mathrm{~m}$ ), and the remaining four were attached to the center of each cage wall (at a depth of $3 \mathrm{~m}$ ). 


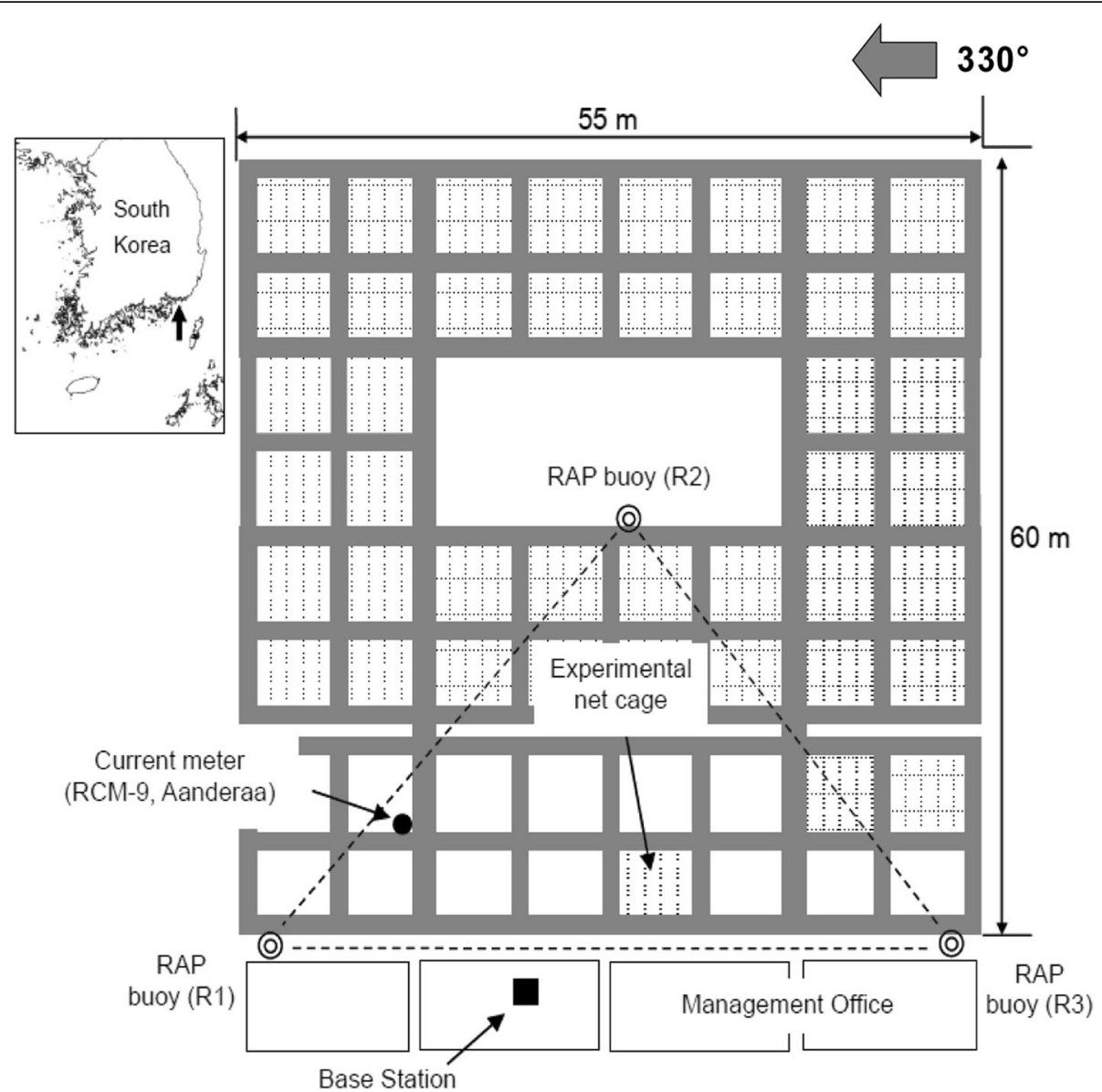

Fig. 1 Experimental setup of radio-linked acoustic positioning system and recording current meter at the marine cage system of the Marine Research Center, Tongyoung, South Korea

In addition, an implantable transmitter (V9P-2H, Amirix Systems Inc.) was used to observe the swimming behavior of chub mackerel within the cage. This tiny transmitter, just $47 \mathrm{~mm} \times 9 \mathrm{~mm}$ and $4.7 \mathrm{~g}$, has a pressure sensor that allowed measurement of the depth at which the fish swim. The transmitter was surgically implanted in the peritoneal cavity of a fish. First, a fish was anesthetized. Next, its abdominal cavity was opened. Then, an ultrasonic transmitter was inserted, and the fish was sutured closed. After the operation, the experimental fish was allowed to recover in a recovery tank and subsequently released in the experimental cage. Two additional mackerel, without transmitters, were also placed in the experimental cage. Fish typically detect up to four neighbors or objects and accordingly determine their swimming direction based on their relative positions (Aoki 1982; Huth and Wissel 1992; Shinchi et al. 2002), placing only a minimum number of fellow fish allowed the experimental fish to freely swim within the entire space of the cage without experiencing crowding. As a result, the positional coordinates received from the experimental fish reflected the cage space within which all three fish could swim. The transmitters used in the experiments have the interval for saving data with $3 \mathrm{~min}$ owing to signal interference from other transmitters.

\section{Experiment and data analysis}

First, the positional coordinates of the transmitters attached to the cage were used to estimate the movement of the cage sides and internal volume loss of the cage. The shape of the cage was measured by the positions of the transmitters at the stand of tide (current speed less than $0.01 \mathrm{~m} / \mathrm{s}$ ), which were estimated by approximating the displacement of each part according to current speed. At this point, the $x$ and $y$ coordinate values, which reflect the displacement of the sides of the cage, were received from VRAP, and the water depth coordinate value, $z$, was obtained by estimating the interior angle between the reference point of each side and its present location based on the origin of the water surface.

The internal volume loss of the cage was estimated by applying the prismoidal formula (Brinker and Minnick 1995), a method to calculate volumes of polygonal 


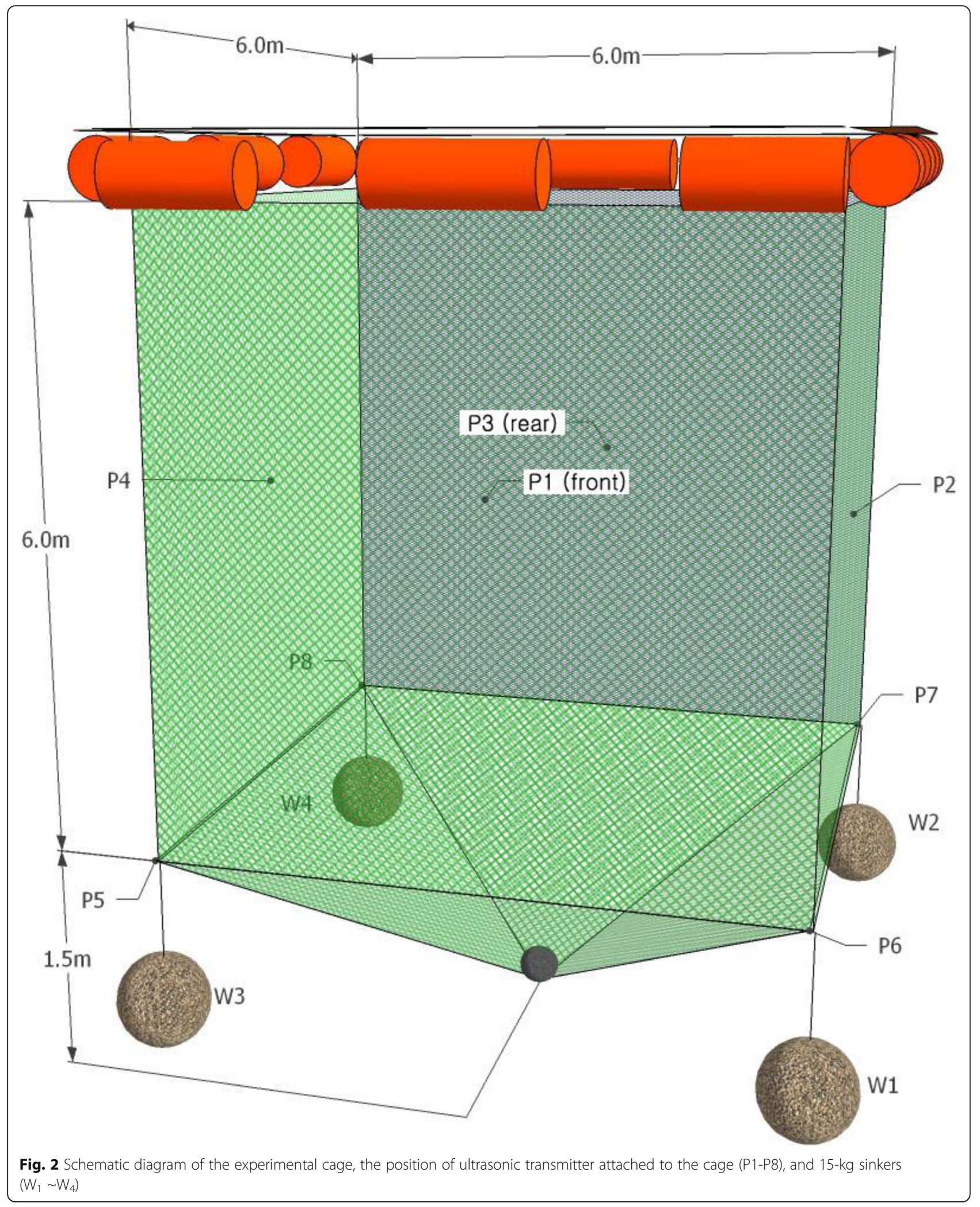


columns. This formula is a simple method of calculating the total volume that uses the cross-sectional area of both ends and the area of the central cross-section when the side is flat. It was convenient to estimate the volume change of the cage using the positions of the eight transmitters attached to the cage. To calculate the volume of the cage, the cage was divided into upper and lower volumes at the 3-m point, and each volume was assumed to be a polygonal column. Assuming the cross-sectional areas of the polygonal columns to be $A_{U}$ and $A_{L}$, the center cross-section between $A_{U}$ and $A_{L}$ to be $A_{m}$, and the distance between both sides to be $\mathrm{L}$, the each volume was estimated by

$$
V=\frac{1}{6} L\left(A_{U}+4 A_{m}+A_{L}\right)
$$

where $A_{U}$ is the top area of the upper polygonal column, $A_{L}$ is the bottom area of the lower polygonal column, and $A_{m}$ is the middle area of the polygonal column.

In the case of actual fishing nets, the sides of a net generally form a smooth surface when the net is moved, as by waves; however, the sides of the net were assumed to be flat in the volume calculation.

The swimming behavior of the fish in the cage was estimated by correlating the coordinates $(x, y, z)$ of the fish received from VRAP with fish cage deformation caused by tide, and the horizontal and the vertical movements of the fish. We also analyzed the change in the depth at which the fish swam during the neap tide and the spring tide by day and night to investigate the patterns of circadian activity rhythms of the fish based on the change in duration and intensity of light.

\section{Results}

Characteristics of the tide in the experimental sea area

Changes in the current direction and speed of the tide on November 7 (neap tide) and December 12 (spring tide), 2017, are shown in Fig. 5. The main axis of the tide was NNW-SSE. The tide with the fastest current speed flowed in the directions of about $330^{\circ}$ and $130^{\circ}$ during the neap tide, as shown in Fig. $3 \mathrm{a}$ and about $340^{\circ}$ and $140^{\circ}$ during the spring tide, as shown in Fig. 3b. The current direction was stable when flowing NNW but volatile when flowing SSE. As shown in Fig. 1, the main axis of the current was almost parallel to one plane of the cage and perpendicular to the other plane because one side of the cage was installed in the direction of $330^{\circ}\left(150^{\circ}\right)$.

The frequencies of extremely slow current speed $(0.01$ $\mathrm{m} / \mathrm{s}$ ), indicating the stand of tide, were $24.6 \%$ and $16.7 \%$ for the neap tide and spring tide, respectively. The maximum instantaneous speed of the neap tide was $0.122 \mathrm{~m} /$ $\mathrm{s}$ in the NNW direction $\left(329.0^{\circ}\right)$ and $0.122 \mathrm{~m} / \mathrm{s}$ in the SSE direction $\left(128.0^{\circ}\right)$, whereas the maximum instantaneous current speed of the spring tide was $0.244 \mathrm{~m} / \mathrm{s}$ in the NNW direction $\left(344.6^{\circ}\right)$ and $0.274 \mathrm{~m} / \mathrm{s}$ in the SSE direction $\left(148.0^{\circ}\right)$. Thus, the maximum instantaneous current speed in the spring tide was about 2.2 times higher than that in the neap tide. The current speed exhibiting the maximum frequency in the neap tide was $0.02 \mathrm{~m} / \mathrm{s}(14.1 \%)$ and that in the spring tide was $0.03 \mathrm{~m} / \mathrm{s}$ $(11.1 \%)$, which were similar to each other; however, $32.6 \%$ of current speed in the spring tide exceeded the

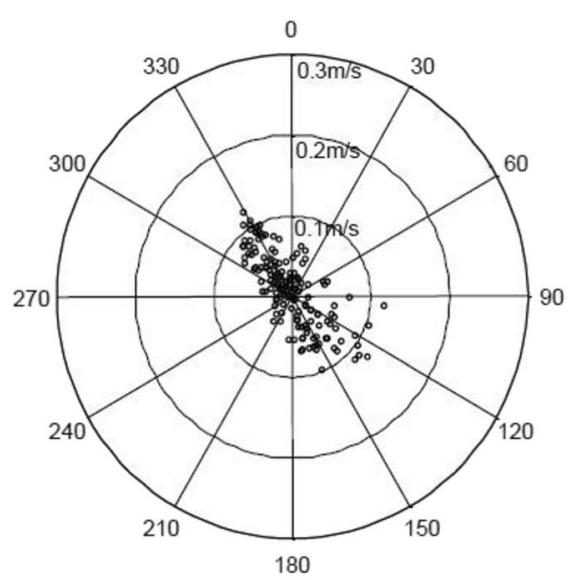

(a)

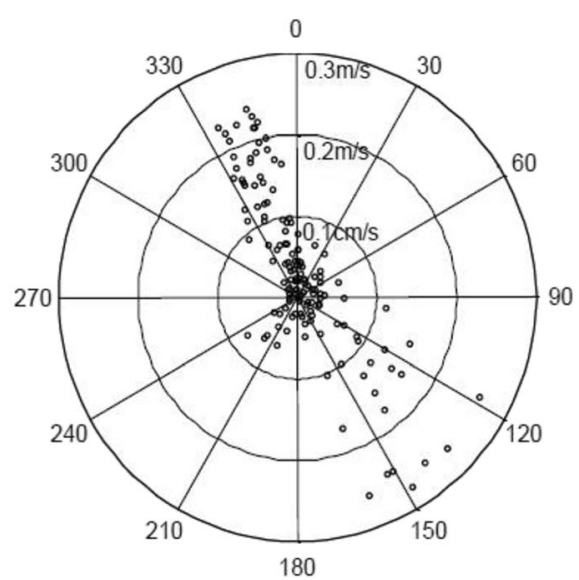

(b)

Fig. 3 Changes in the current direction and current speed of the tide during the a neap tide (on November 7, 2016) and $\mathbf{b}$ spring tide (December 12, 2016) 
maximum instantaneous speed in the neap tide. From these results, it can be concluded that the environmental conditions of the two experimental days were very different because the current speed distributions between the two experimental days showed significant differences.

\section{Fish cage deformation and volume loss}

The three-dimensional cage deformation caused by the tide is illustrated in Fig. 4. The cage deformation was analyzed for the main axis (NNW) of the tide within a range of $\pm 15^{\circ}$, as shown Fig. 3 , in which the current direction that most affected cage deformation was stable. Figure 4 a depicts the cage shape at the stand of tide, showing that there was hardly any influence by the tide, while Fig. 4b shows the shape of the cage at the maximum current speed in the neap tide; the arrow below the cage represents current direction. As the current speed increased, the net surface perpendicular to the current direction encountered a large amount of fluid resistance and moved accordingly, which led to fish cage deformation; however, the shape of the net surface parallel with the current direction did not change much. Each corner of the lower part of the cage showed less

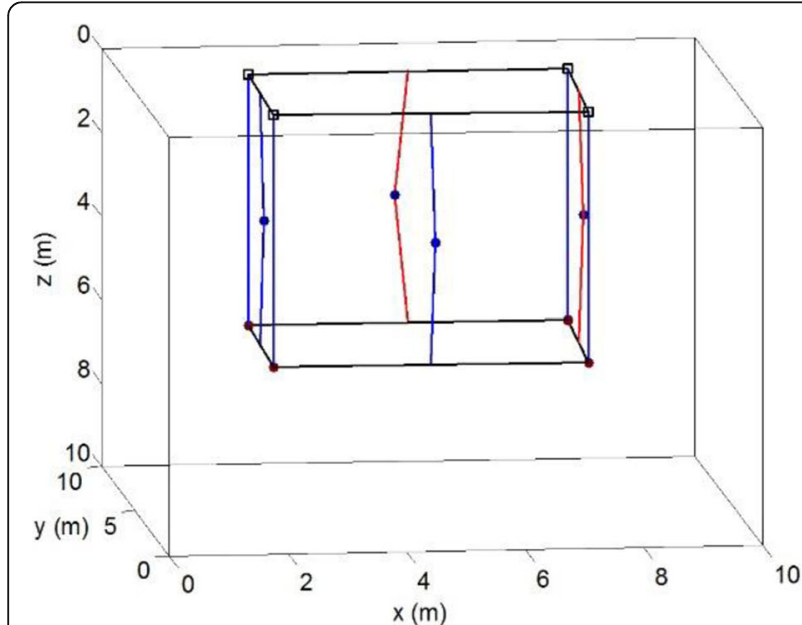

(a)

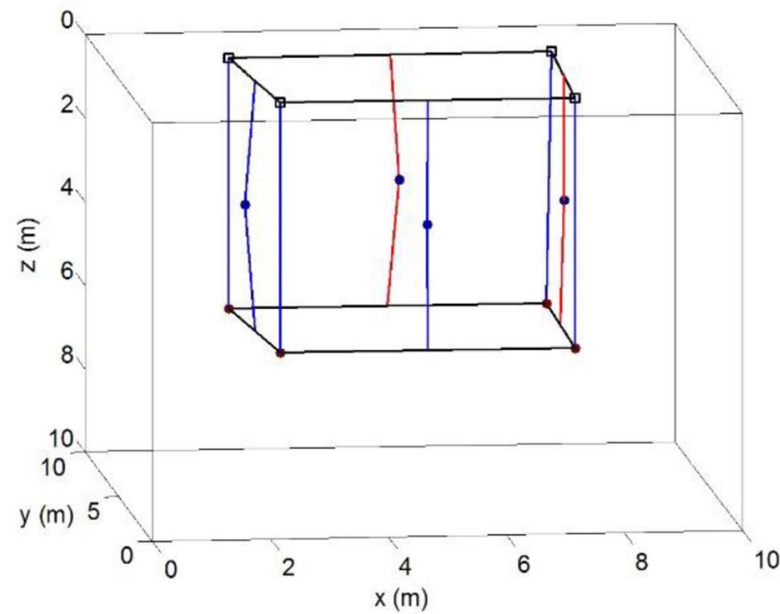

(c)

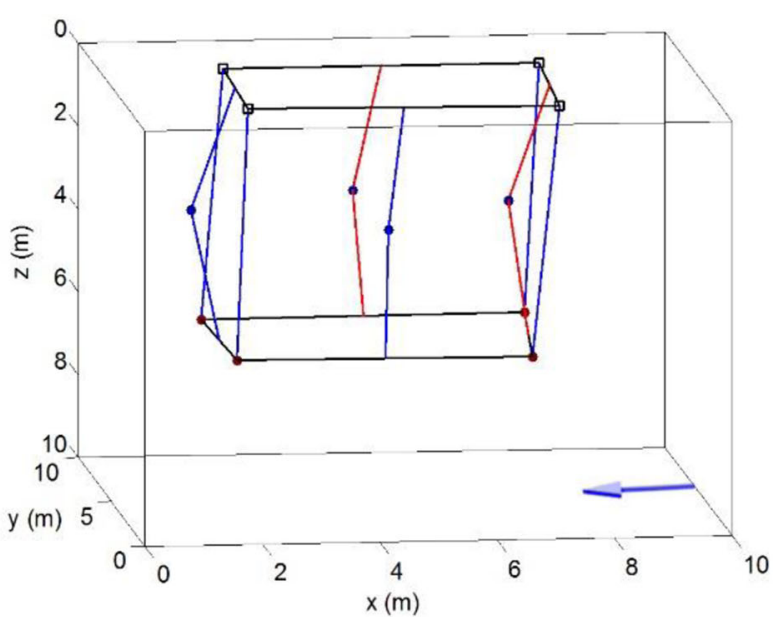

(b)

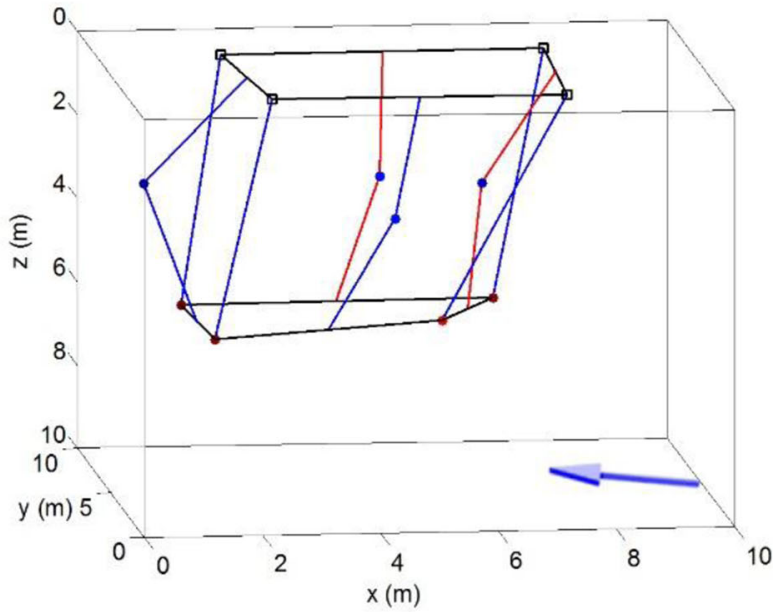

(d)

Fig. 4 Comparison of the fish cage deformation between neap tide and spring tide. a Stand of tide (neap tide). b Max. current speed to NNW ( $\bar{V}$ $\left.=0.111 \mathrm{~m} / \mathrm{s}, \bar{D}=327.4^{\circ}\right)$. $\mathbf{c}$ Stand of tide (spring tide). $\mathbf{d}$ Max. current speed to NNW $\left(\bar{v}=0.221 \mathrm{~m} / \mathrm{s}, \bar{D}=343.1^{\circ}\right.$ ) 
movement than did the net surface because of the sinker (weight) at the lower part of the cage. The right corner, which received the current first, moved slightly more than did the left corner. Nevertheless, the shape of the cage did not exhibit considerable deformation, even with the maximum current speed, in the neap tide.

Cage deformation in the spring tide is depicted in Fig. $4 \mathrm{c}$ and $\mathrm{d}$, the former showing deformation during the stand of tide and the latter showing deformation at the maximum current speed. As seen in Fig. 4c, the shape of the cage at the stand of tide in the spring tide was similar to that in the stand of tide in the neap tide (Fig. 4a), but the cage was greatly deformed at the time of the maximum current speed in the spring tide. Figure $4 \mathrm{~d}$ shows that at the time of the maximum current speed, the center of the net perpendicular to the direction of the tide was greatly displaced. At this time, the net surface parallel with the tide was slightly displaced as well. The lower right corner, moreover, had greater deformation than the other corners, so, the shape of the cage was entirely distorted from its original form of a tetragonal column (cube). The reason for this was that one side of the cage was in the direction of $330^{\circ}$, but the current direction in the spring tide was about $344^{\circ}$, which means it flowed from the lower right to the upper left at an angle of about $10^{\circ}$. As a result, it is inferred that the fluid resistance at the lower right corner was the largest.

The volume loss of the cage, as calculated by the prismoidal formula, at times of relatively stable current speed in the NNW direction, is shown in Fig. 5. Based on its shape at the stand of tide, the volume loss was
$2.2 \%$ at a current speed of $0.088 \mathrm{~m} / \mathrm{s}$, about $4.9 \%$ at $0.111 \mathrm{~m} / \mathrm{s}$, and $5.8 \%$ at $0.155 \mathrm{~m} / \mathrm{s}$ (the maximum current speed during the neap tide), whereas, it was $7.3 \%$ at the maximum current speed of $0.221 \mathrm{~m} / \mathrm{s}$ in the spring tide. The cage was greatly deformed as the shape of the net surface perpendicular to the current direction changed, as shown in Fig. 4; however, it was inferred that there was only a little internal volume loss owing to the sinkers attached to each corner of the cage to maintain its shape.

\section{Changes in the swimming behavior of cultured fish}

The swimming behavior of chub mackerel was significantly different between the neap tide and the spring tide, as was the shape of the cage. The threedimensional underwater positions of the fish are shown in Fig. 6; Fig. 6a and b represents the distribution of the fish in the neap tide and in the spring tide, respectively. The overall distribution pattern of the fish in Fig. 6a during the neap tide shows that they moved closer to the water's surface occasionally, but mostly stayed in the lower part of the cage. The shape of the distribution took the form of a discus, as the fish spent most of their time in the lower part of the cage and swam in a circle. This pattern verifies that the cultured chub mackerel in the cage shared characteristics of fish under regular conditions (Beveridge 2004). Thus, it is inferred that the cultured fish here exhibited relatively stable swimming behavior in the cage during neap tide.

The shape of the distribution of the cultured fish in the spring tide (Fig. 6b), however, showed a significantly different shape from that in the neap tide (Fig. 6a). The

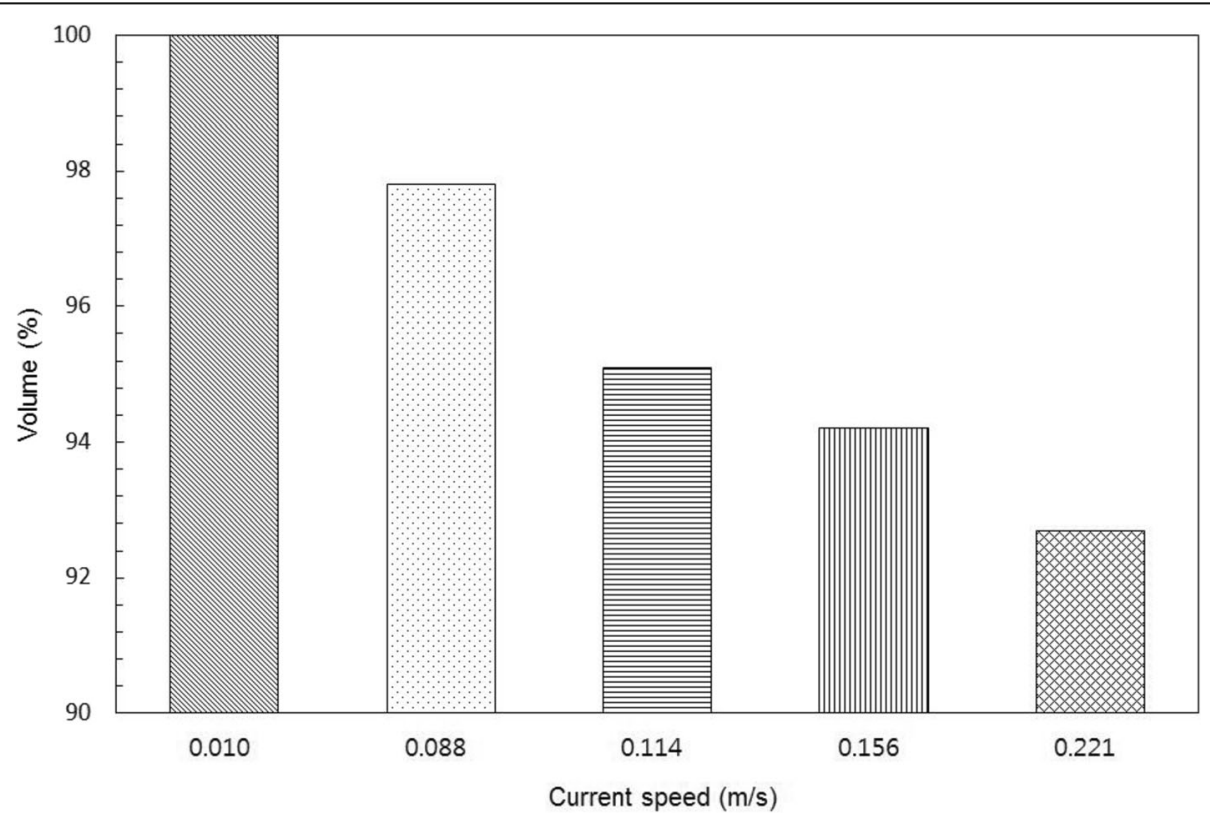

Fig. 5 Volume loss of cage caused by current speed ( $\square$ neap tide, $\mathbf{m}$ spring tide) 


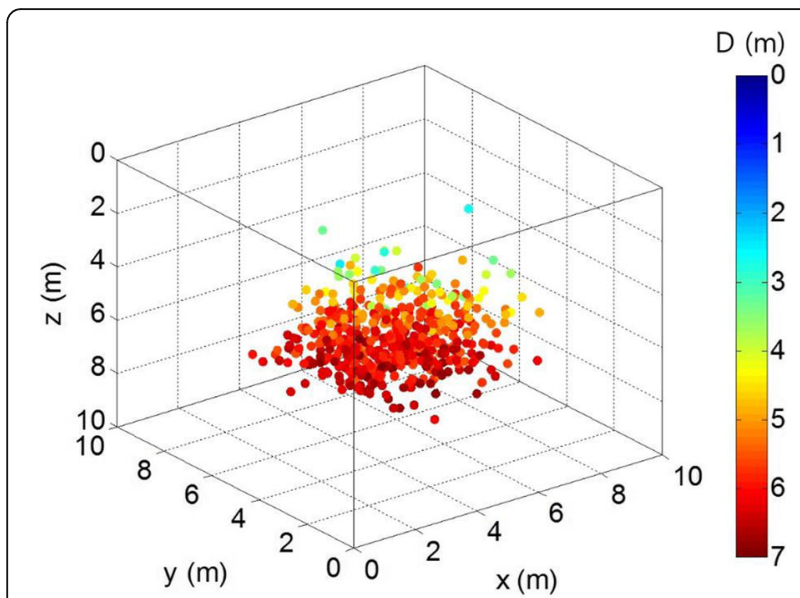

(a)

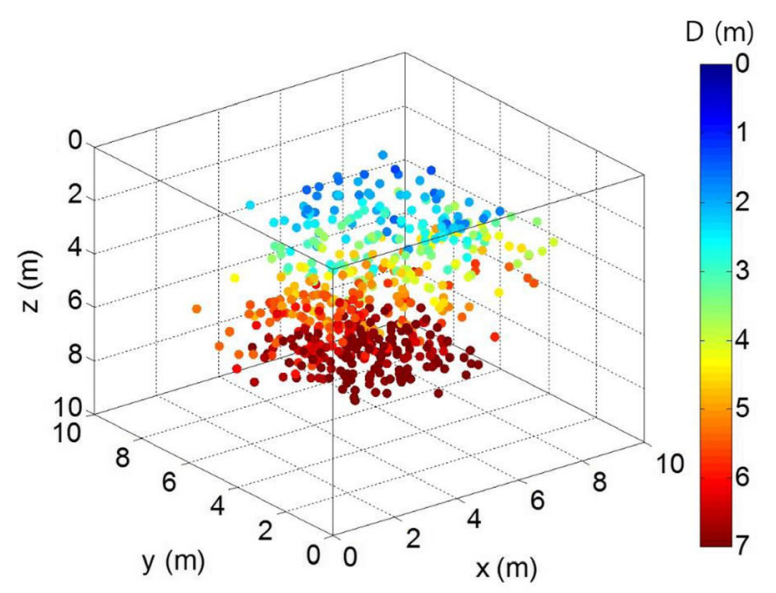

(b)

Fig. 6 Comparison of the swimming space of the cultured chub mackerel between the neap tide and the spring tide. a Neap tide. $\mathbf{b}$ spring tide

position distribution pattern of the fish, which indicates their swimming behavior, was not primarily near the lower part of the cage in spring tide, unlike that in neap tide, and took the form of a long discus in the direction of the $x$-axis. The reason for this is that the main axis of the current was almost parallel with the $x$-axis, which limited and deformed the swimming area of the fish owing to the displacement of the net surface perpendicular to the current direction. It is inferred that the fish kept swimming aggressively to maintain their position against the fast current in the spring tide. These factors prevented the fish from showing their stable swimming behavior in the lower part of the cage as in the neap tide; instead, they frequently moved to areas near the surface of the sea, above the depth of $3 \mathrm{~m}$, which led to an increased change in their swimming pattern.

The results of the analysis of the three-dimensional distributions of the cultured fish by the current speed conducted to determine the effect of the cage deformation on their swimming behavior is represented in Fig. 7. Figure 7a shows the position distribution of the fish at the stand of tide in neap tide, in which it is assumed that the fish generally stayed below the depth of $4 \mathrm{~m}$ and swam across most of the horizontal area of the cage. The fish moved to the left because of cage deformation; however, they did not change their depth much and stayed in the lower part of the cage, at the time of the maximum current speed in the neap tide, as shown in Fig. 7b.

Contrarily, the fish swam in the central part of the cage and frequently moved to the upper part of the cage, at the maximum current speed in the spring tide, as shown in in Fig. 7c. Such behavior occurred at current speeds of $0.14-0.16 \mathrm{~m} / \mathrm{s}$, in which the fish also moved to the right because of cage deformation, as shown in Fig. $7 \mathrm{~d}$. The swimming area of the fish moved further to the right at the maximum current speed in the spring tide as cage deformation increased, as shown in in Fig. 7e. At this time, they stayed mostly around the depth of $5 \mathrm{~m}$. At these times, the fish appeared frequently in the central part of the left side, but did not appear in the bottom right side of the cage due to the severe cage deformation on the left net surface and the bottom right side of the cage, as shown in Fig. 4d.

In conclusion, in the neap tide, the distribution of the cultured chub mackerel was mainly concentrated in deep water, near the lower part of the cage, and the center of the distribution shifted slightly to the right side owing to the slight cage deformation caused by the small range of changes in the current speed. In the case of the spring tide, however, the fish did not stay in the lower part of the cage even at the stand of tide; instead, they moved to other depths, where they had more space in which to swim freely, as the upper part of the cage was significantly deformed.

The changes in swimming depth over time in the neap tide and in the spring tide are depicted in Fig. 8. As shown in Fig. 4, there was very little cage deformation during the neap tide; so, the changes in swimming depth can be inferred to be fish reaction to light conditions within the cage. The mean swimming depth of the fish during the neap tide did not vary significantly between day time $(6.1 \mathrm{~m})$, as shown in Fig. $8 \mathrm{a}$, and night time $(5.9 \mathrm{~m})$, as shown in Fig. 8b. The distribution of fish during the neap tide was identical between day and night, and they were always concentrated in the lower part of the cage. During spring tide, the fish remained primarily at a depth of $6.8 \mathrm{~m}$ during the day (Fig. 8c), deeper than 


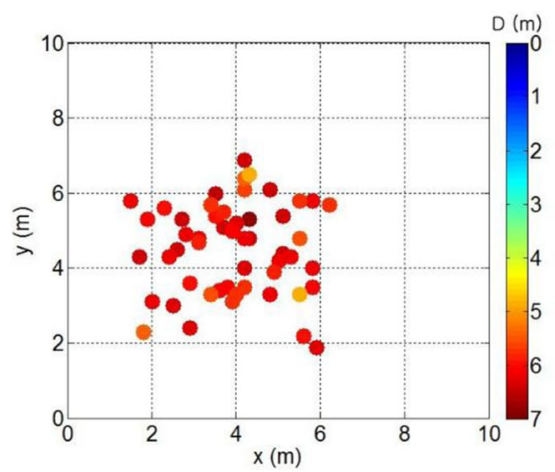

(a)

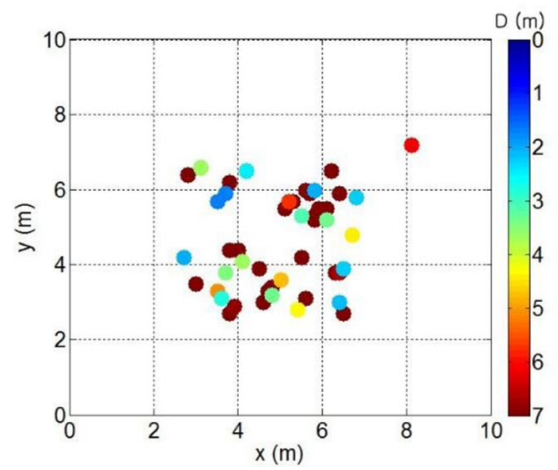

(c)

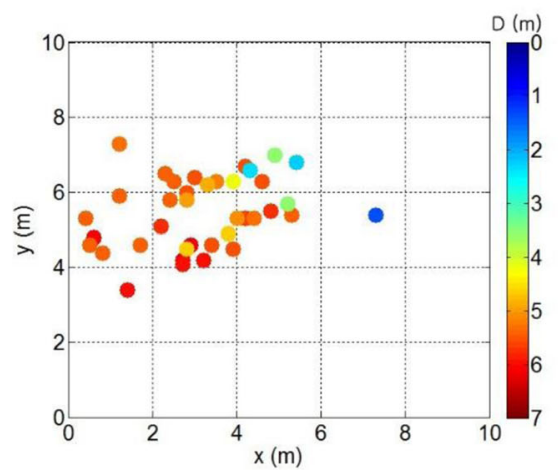

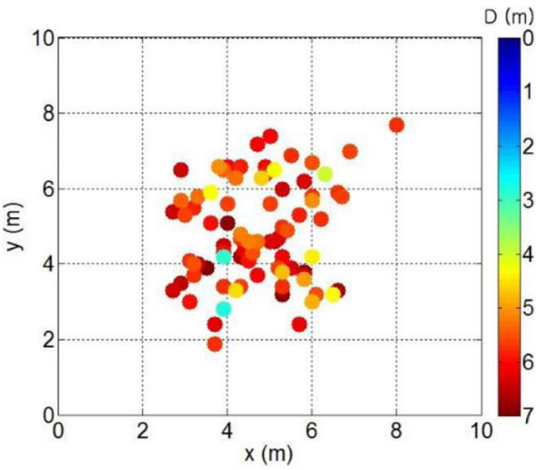

(b)

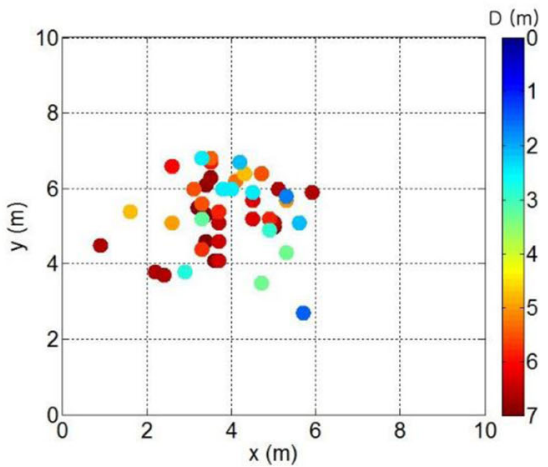

(d)

(e)

Fig. 7 Comparison of the swimming behavior of the cultured chub mackerel affected by cage deformation. a $v<0.1 \mathrm{~m} / \mathrm{s}$ (stand of tide) in the neap tide. $\mathbf{b} v=0.10-0.122 \mathrm{~m} / \mathrm{s}$ in the neap tide. $\mathbf{c} v<0.1 \mathrm{~m} / \mathrm{s}$ (stand of tide) in the spring tide. $\mathbf{d} v=0.14-0.16 \mathrm{~m} / \mathrm{s}$ in the spring tide. e $v=0.2-$ $0.223 \mathrm{~m} / \mathrm{s}$ in the spring tide

that in neap tide. The fish showed relatively stable swimming depth, but occasionally moved upwards, to a depth of approximately $5 \mathrm{~m}$. However, at night in spring tide, the fish tended to frequently move upwards toward the surface of the sea (Fig. 8d). It can be inferred that the fish moved to a safer space because they could not stably stay near the lower part of the cage owing to the considerably large cage deformation caused by the high current speed. In addition, the swimming distribution at night time during the spring tide showed a significantly different shape (Fig. 8d). The mean swimming depth of the fish at night during the spring tide was $3.7 \mathrm{~m}$, and they moved evenly between the depths of $1 \mathrm{~m}$ and $6 \mathrm{~m}$. In other words, their swimming was not concentrated at 


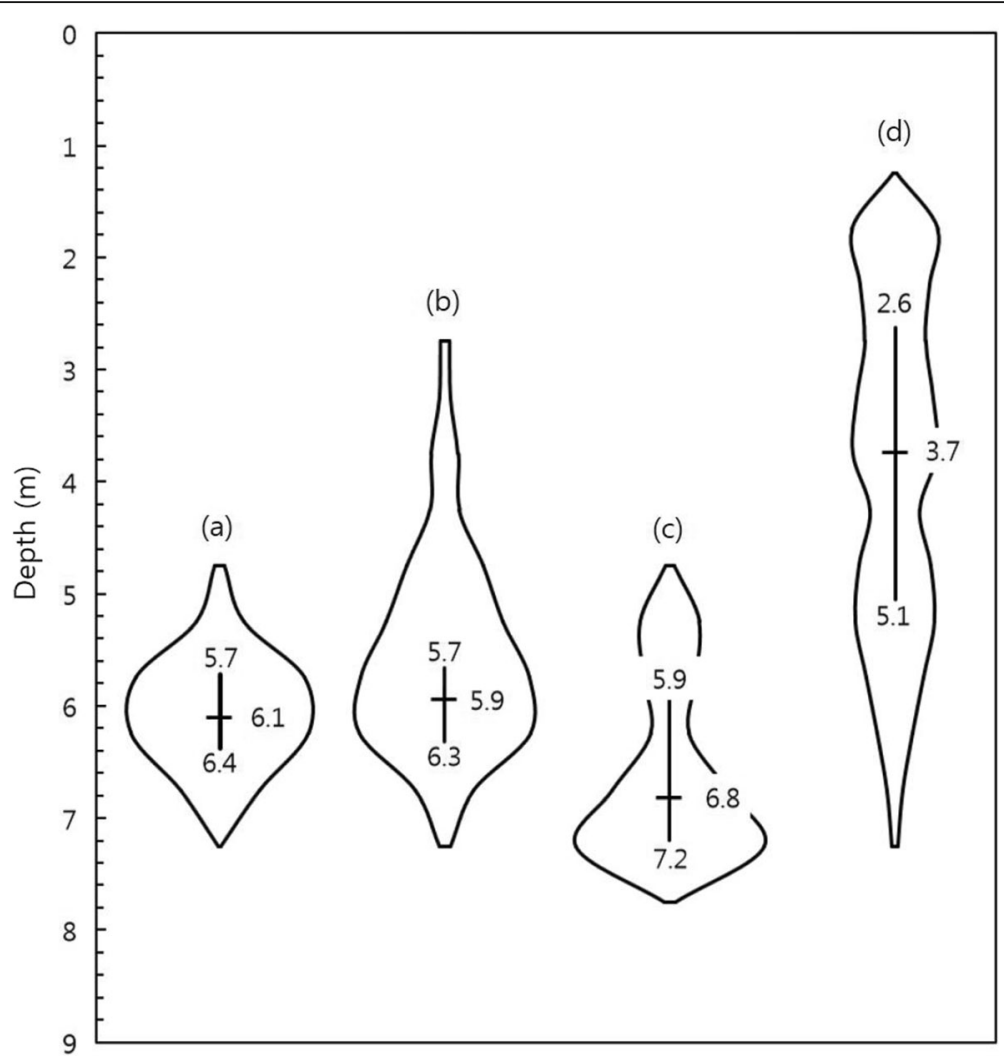

Fig. 8 Comparison of swimming depth distribution during the neap and spring tide. a Neap tide/day. b Neap tide/night. c Spring tide/day. d Spring tide/night

one specific depth. Thus, the fish did not show stable swimming behavior at night in the spring tide, as opposed to that in the neap tide. It is further inferred that they had to make frequent movements between the upper part and the lower part of the cage. Assuming that the swimming depth at night in the neap tide is natural swimming behavior for fish in general, the behavior of the experimental fish was significantly affected by cage deformation at night in the spring tide owing to the extreme changes in the current speed and the cage sides not being visible to the fish.

In sum, the behavior of the cultured chub mackerel within the cage was limited by the shape of the cage. They were not affected much by the minor cage deformation in the neap tide, in which the current speed was slow. However, the larger cage deformation in the spring tide appeared to affect their swimming behavior. This influence was greater at night time, when their vision was limited.

\section{Discussion}

Individual-based measurements enable us to understand the synchronous mechanisms by which fish cope with environmental signals that cause changes in their behavior in a production environment (Oppedal et al. 2011).
Our results indicate that cage deformation significantly affects the swimming behavior pattern of cultured chub mackerel. The fish generally swam in a circle in the neap tide but moved to one side of the cage because of cage deformation in the spring tide. Moreover, the fish appeared to make frequent movements to the upper and lower parts of the cage in the spring tide; such changes in the swimming depth were most pronounced at night in the spring tide.

The degree of cage deformation is affected by the direction of the current, waves, shape of the mesh and size of the net, position and weight of the sinkers, and current speed. One study measured cage deformation and calculated the volume loss due to the current using an underwater sensor; the volume loss of the cage was $20 \%$ even at a low current speed of $0.2 \mathrm{~m} / \mathrm{s}$ and up to $40 \%$ at a current speed of $0.35 \mathrm{~m} / \mathrm{s}$ (Lader et al. 2008). Another study, on designing the shape of the sinkers attached to the cage, showed that the volume loss of the cage was significant with current speeds greater than 0.2 $\mathrm{m} / \mathrm{s}$ (Kim et al. 2001a). In our study, there was a volume loss of about $8 \%$ in the spring tide when the current speed exceeded $0.2 \mathrm{~m} / \mathrm{s}$. The cage used in our study was tetragonal (a cube), which was different from the shape of the cage used in the previous study (Lader et al. 
2008). In addition, the sinkers attached to each corner may have minimized cage deformation. At a low current speed, the fish generally showed very stable movement under the net in the cage. However, when the current speed increased, they tended to swim to the surface upon deformation of cage shape. This is believed to have increased the stress index of the fish, resulting in growth and other adverse effects. The adverse effects of these changes in behavior of the fish on the shape of the cage have been discussed in other studies (Lader et al. 2008). Moreover, although the volume loss was only $7.3 \%$, the impact on the fish caused by the volume loss is likely to be greater when considering the situation wherein large numbers of fish are farmed in the actual fish cage.

The cultured chub mackerel in the experimental cage generally swam in a circle during the day, while avoiding the deep corners. Visual observation of highly populated cages showed that they occasionally swim near the surface; however, they usually swim near the lower part of the cage if there is enough space, as there was in this study.

In our study, the fish mainly preferred the lower part of the cage; however, they tended to swim at shallower depths at night in the spring tide, when their vision was limited. There were no significant changes in the water temperature, cloudiness, or conductivity by the measurement, which could have influenced the swimming depth distribution of the fish, at the time of this field experiment. Thus, the vertical changes in the swimming depth of the observed fish might have been caused by their circadian rhythm and deformation of the cage (Føre et al. 2009; Johansson et al. 2014).

Scale-down model experiments and simulations are widely used to estimate fish cage deformation according to the design of the net. Survey experiments are imperative to analyze the swimming behavior of the fish in these cages. Simultaneous observations of fish swimming behavior and measurements of cage deformation using a current underwater telemetry system will require extensive data collection over long durations. The transmitters used in the experiments have the interval for saving data with $3 \mathrm{~min}$ owing to signal interference from other transmitters. Even though the data collection interval was not short, the fish continuously and repeatedly swam in an identical pattern in a small space, and the shape of the cage did not rapidly change because of the current; so, the data was adequate to detect the pattern. Since we were able to select several time periods with slight changes in the current, it was sufficient for us to estimate the swimming area of the fish.

In our results, the accuracy of the underwater telemetry system was extremely important in verifying and evaluating the correlation between the changes in the current and cage deformation. The underwater telemetry system we used estimates the underwater position of an object using the time delay of acoustic arrival, though the accuracy varies based on the output level of the transmitter or decreases and increases in signals (Baras and Lagardere 1995). Previous studies show that the VRAP system is accurate to about $1-2 \mathrm{~m}$ when a transmitter station is installed using an anchor. Thus, such a system is unavoidably affected by the changes in baseline due to the movement of the station. In a previous study, we measured signals from a fixed transmitter attached to a cage in a quiet sea, in which the two-distance root mean square ( $2 \mathrm{drms}$ ) was $0.8 \mathrm{~m}$ (Tae and Shin 2006). The standard deviations of the $x$-, $y$-, and $z$-axes were $0.2,0.4$, and $1.0 \mathrm{~m}$, respectively. The baseline in that experiment was between 12 and $14 \mathrm{~m}$, which was considerably shorter than that in this study.

Swimming area in a deformed cage is affected by visual stimulation (Ehrenberg and Steig 2003). Cage deformation affects the yield and health of the cultured fish by reducing the space in which they can swim (Lader et al. 2008). In this study, we verified that cultured chub mackerel frequently swam near the surface of the water owing to cage deformation, and that they were hindered from stably resting and swimming because of limited space in the cage. In recent years, aquafarms have begun moving to the open sea because of the contamination of coastal water from cage-based fish culture (Kim et al. 2001b); therefore, cage deformation and changes in fish behavior due to the current speed are very important. With the new trend in the aquaculture industry, it is imperative to conduct in-depth studies on the influences of current and waves on marine cages, and the fish reared in them.

\section{Conclusions}

The behavioral change in cultured fish according to changes in shapes of tetragonal small-sized fish cages based on the tide was measured using the 3D underwater position measurement system and analyzed. The swimming volume of the fish due to net deformation is influenced by visual stimuli, and the net deformation affects the yield and health of cultured fish by reducing the volume. Furthermore, fish are more likely to swim close to the water due to deformation of the net, and limited within the area where swimming is possible, thus confirming that the cultured fish are disturbed to stable rest and swimming. In recent years, since the waters occupied by the cage aquaculture are becoming more polluted and moving to the offshore, the shape changes of the net and the behavior characteristics of the fish by the flow rate will become more important. Regarding the new trends of this aquaculture, it is necessary to investigate in depth the relationship between the increasing influence of currents and waves on net and fish. 


\section{Acknowledgements}

Not applicable

\section{Authors' contributions}

BK Hwang carried out the field experiment and participated in drafted the manuscript. J Lee analyzed the experimental data, participated in drafted, and finalized the manuscript. HO Shin carried out the field experiment. All authors read and approved the final manuscript.

\section{Funding}

Not applicable

\section{Availability of data and materials}

Not applicable

\section{Ethics approval and consent to participate}

Not applicable

\section{Consent for publication}

Not applicable

\section{Competing interests}

The authors declare that they have no competing interests.

\section{Author details}

${ }^{1}$ Division of Marine Industry Transportation Science and Technology, Kunsan National University, 558 Daehak-ro, Gunsan 54150, Korea. ${ }^{2}$ Department of Marine Porduction of Management, Chonnam National University, 50 Daehak-ro, Yeosu 59626, Korea. ${ }^{3}$ Division of Marine Production System Management, Pukyong National University, 45 Yongso-ro, Busan 48513, Korea.

Received: 10 February 2020 Accepted: 30 March 2020

Published online: 24 April 2020

\section{References}

Anras MB, Lagardère JP. Measuring cultured fish swimming behavior: first results on rainbow trout using acoustic telemetry in tanks. Aquaculture. 2004;240: 175-86. https://doi.org/10.1016/j.aquaculture.2004.02.019.

Aoki I. A simulation study on the schooling mechanism in fish. B Jpn Soc Sci Fish. 1982;48:1081-8. https://doi.org/10.2331/suisan.48.1081.

Baras E, Lagardere JP. Fish telemetry in aquaculture: review and perspectives. Aquacult Int. 1995;3:77-102. https://doi.org/10.1007/BF00117876.

Beveridge M. Cage aquaculture. 3rd ed. Oxford: Wiley-Blackwell; 2004

Bi CW, Zhao YP, Dong GH, Cui Y, Gui FK. Experimental and numerical investigation on the damping effect of net cages in waves. J Fluids Struct. 2015;55:122-38. https://doi.org/10.1016/j.jluidstructs.2015.02.010.

Brinker RC, Minnick R. The surveying handbook. 2nd ed. New York: SpringerVerlag; 1995.

Conte FS. Stress and the walfare of cultured fish. Appl Anim Behav Sci. 2004;86: 205-23. https://doi.org/10.1016/j.applanim.2004.02.003.

Cubitt KF, Churchill S, Rowsell D, Scruton DA and McKinley RS. 2005. 3dimensional positioning of salmon in commercial sea cages: assessment of a tool for monitoring behaviour. In: Spedicato MT, Lembo G, Marmulla G (ed) Proceedings of the fifth Conference on Fish Telemetry, Ustica, Italy, 9-13 June 2003.

Ehrenberg JE, Steig TW. Improved techniques for studying the temporal and spatial behavior of fish in a fixed location. ICES J Mar Sci. 2003;60:700-6. https://doi.org/10.1016/S1054-3139(03)00087-0.

Føre M, Dempster T, Alfredsen JA, Johansen V, Johansson D. Modelling of Atlantic salmon (Salmo salar L.) behaviour in sea-cages: a Lagrangian approach. Aquaculture. 2009;288:196-204. https://doi.org/10.1016/j. aquaculture.2008.11.031

Gui F, Li Y, Dong G, Guan C. Application of CCD image scanning to sea-cage motion response analysis. Aquacult Eng. 2006;35:179-90. https://doi.org/10 1016/j.aquaeng.2006.01. 003.

Huth A, Wissel C. The simulation of the movement of fish schools. J Theor Biol. 1992;156:365-85. https://doi.org/10.1016/50022-5193(05)80681-2.

Hwang BK, Shin HO. Analysis on the movement of bag-net in set-net by acoustic telemetry techniques. Fish Sci. 2003;69:300-7. https://doi.org/10.1046/.1444. 2906.2003.00621.x.
Johansson D, Laursen F, Fernö A, Fosseidengen JE, Klebert P, Stein LH, Vagseth T, Oppedal F. The interaction between water currents and salmon swimming behaviour in sea cages. Plos One. 2014;9:e97635. https://doi.org/10.1371/ journal.pone.0097635.

Jørgensen T, Løkkeborg S, Fernö A, Hufthammer M. Walking speed and area utilization of red king crab (Paralithodes camtschaticus) introduced to the Baren Sea coastal ecosystem. Hydrobiologia. 2007;582:17-24. https://doi.org/ 10.1007/978-1-4020-6237-7_3.

Juell JE, Westerberg H. An ultrasonic telemetric system for automatic positioning of individual fish used to track Atlantic salmon (Salmo salar L.) in a sea cage. Aquacult Eng. 1993;12:1-18. https://doi.org/10.1016/0144-8609(93)90023-5.

Kim TH, Kim JO, Kim DA. Deformation of cage nets against current speed and optimal design weight of sinker. J Kor Soc Fish Tech. 2001a;37:45-51.

Kim TH, Kim JO, Ryu CR. Dynamic motions of model fish cage systems under the conditions of waves and current. J Kor Soc Fish Tech. 2001 b;34:43-50.

Lader P, Dempster T, Fredheim A, Jensen $\varnothing$. Current induced net deformation in full-scale sea-cages for Atrantic salmon (Salmo salar). Aquacult Eng. 2008;38: 53-65. https://doi.org/10.1016/j.aquaeng.2007.11.001.

Lee CW, Kim YB, Lee GH, Choe MY, Lee MK, Koo KY. Dynamic simulation of a fish cage system subjected to currents and waves. Ocean Eng. 2008;35:1522-32. https://doi.org/10.1016/j.oceaneng.2008.06.009.

Lee CW, Lee J, Park SB. Dynamic behavior and deformation analysis of the fish cage system using mass-spring model. China Ocean Eng. 2015;29:311-24. https://doi.org/10.1007/s13344-015-0022-2.

Lee J, Hwang BK, Choe MY. Aquaculture design for healthier fish. Sea Technol. 2017:58:23-6.

Miyamoto Y, Uchida K, Orii R, Wen Z, Shiode D, Kakihara T. Three-dimensional underwater shape measurement of tuna longline using ultrasonic positioning system and ORBCOMM buoy. Fish Sci. 2006;72:63-8. https://doi. org/10.1111/j.1444-2906.2006.01117.x.

Oppedal F, Dempster T, Stein LH. Environmental drivers of Atlantic salmon behavior in sea-cage: a review. Aquaculture. 2011;311:1-18. https://doi.org/ 10.1016/j.aquaculture.2010. 11.020.

Shinchi T, Kitazoe T, Nishimura H, Tabuse M, Azuma N, Aoki I. Fractal evaluation of fish school movements in simulations and real observations. Artificial Life and Robotics. 2002;6:36-43. https://doi.org/10.1007/BF02481207.

Tae JW, Shin HO. Acoustic analysis of volume variation in a bag-net within a setnet. Fish Res. 2006;80:263-9. https://doi.org/10.1016/j.fishres.2006.03.030.

Zhao YP, Wang XX, Decew J, Tsukrov I, Bai XD. Comparative study of two approaches to model the offshore fish cages. China Ocean Eng. 2015;29:459, 472. https://doi.org/10.1007/ s13344-015-0032-0.

\section{Publisher's Note}

Springer Nature remains neutral with regard to jurisdictional claims in published maps and institutional affiliations.

Ready to submit your research? Choose BMC and benefit from:

- fast, convenient online submission

- thorough peer review by experienced researchers in your field

- rapid publication on acceptance

- support for research data, including large and complex data types

- gold Open Access which fosters wider collaboration and increased citations

- maximum visibility for your research: over $100 \mathrm{M}$ website views per year

At BMC, research is always in progress.

Learn more biomedcentral.com/submissions 